\title{
INTERSECCIONALIDADE E PENSAMENTO FEMINISTA: As contribuições históricas e os debates contemporâneos acerca do entrelaçamento de marcadores sociais da diferença
}

\author{
Carlos Eduardo Henning ${ }^{1}$
}

\begin{abstract}
Resumo
Este artigo expõe uma revisão sucinta dos debates encetados nas últimas décadas acerca da noção de interseccionalidade entre as diversas abordagens do pensamento feminista, dos estudos de mulheres e das teorias de gênero contemporâneas. Partindo das contribuições dos "black feminisms", apresenta algumas visões sobre o contexto de formação do debate interseccional nos Estados Unidos e no Reino Unido e a seguir estabelece as principais vertentes de trabalho atualmente. Embasado em um levantamento bibliográfico de dezenas de artigos, ensaios e livros publicados nos últimos anos nos EUA e na Europa, este texto procura contribuir com uma "sumarização" de algumas das principais contribuições que a análise interseccional tem oferecido ao pensamento feminista e à teoria social como um todo, assim como propor a noção de "agência interseccional". Por fim, são apresentadas algumas considerações críticas a determinadas características que atravessam o campo e que geram questionamentos ainda em aberto.
\end{abstract}

Palavras-Chave: Interseccionalidade. Marcadores sociais da diferença. Desigualdades. Agência interseccional.

1 Docente do Programa de Pós-Graduação em Antropologia Social e da Faculdade de Ciências Sociais da UFG - Universidade Federal de Goiás. Pesquisador do Ser-Tão, Núcleo de Estudos e Pesquisas em Gênero e Sexualidade. E-mail: carloseduardohenning@gmail.com 
INTERSECTIONALITY AND FEMINIST THOUGHT:

HISTORICAL CONTRIBUTIONS AND CONTEMPORARY DEBATES ABOUT THE

INTERLOCKING OF SOCIAL MARKERS OF DIFFERENCE

\begin{abstract}
This article presents a brief review of the debates concerning the concept of intersectionality among various approaches of the contemporary feminist thought, the women's studies and the gender theories. Based on the initial contributions of the "Black Feminisms", this text aims to propose a panorama of the emergent context of the intersectional debate and its main strands of work in the US and UK. Grounded in a literature review of dozens of recent articles, essays and books published in the US and Europe, this text seeks to offer a "summarization" of some of the major contributions that the intersectional analysis has offered to the feminist thought and the social theory as a whole, as well as to propose the notion of "intersectional agency". Finally, the text presents some critical considerations regarding certain characteristics that cross the field and that are still generating some important questions.
\end{abstract}

Keywords: Intersectionality. Social markers of difference. Inequalities. Intersectional agency.

\title{
INTRODUÇã̃ ${ }^{2}$
}

A interseccionalidade inicia um processo de descoberta, nos alertando para o fato de que o mundo a nossa volta é sempre mais complicado e contraditório do que nós poderíamos antecipar. (...) Ela não provê orientações estanques e fixas para fazer a investigação feminista (...). Ao invés disso, ela estimula nossa criatividade para

2 Este artigo é uma versão ampliada de papers apresentados em dois eventos acadêmicos internacionais: o XI Congresso Luso-Afro-Brasileiro de Ciências Sociais realizado em 2011, na cidade de Salvador, Bahia; e também na X Reunião de Antropologia do Mercosul realizada em 2013 em Córdoba, Argentina. A oportunidade de compartilhar esse texto em suas versões iniciais em ambos os eventos foi de grande valia para a forma final deste artigo. Agradeço também aos generosos comentários e sugestões de Regina Facchini, Isadora Lins França, Glauco Ferreira e Giancarlo Cornejo Salinas a versões preliminares deste artigo. E, por fim, aos comentários de pareceristas a este texto uma vez submetido à Mediações, os quais foram também muito importantes para os seus desenvolvimentos finais. 
olhar para novas e frequentemente não-ortodoxas formas de fazer análises feministas. A interseccionalidade não produz uma camisa-de-forças normativa para monitorar a investigação (...) na busca de uma 'linha correta'. Ao invés disso, encoraja a cada acadêmica feminista a se envolver criticamente com suas próprias hipóteses seguindo os interesses de uma investigação feminista reflexiva, crítica e responsável (DAVIS, 2008, p. 79) ${ }^{3}$.

Neste artigo meu interesse reside em expor um panorama sucinto dos debates encetados nas últimas décadas acerca de uma categoria que tem atraído grande atenção principalmente entre as diversas abordagens do pensamento feminista, dos estudos de mulheres e das teorias de gênero contemporâneas: a interseccionalidade ${ }^{4}$. Tal termo alude às reflexões e teorizações sobre a "multiplicidade de diferenciações que, articulando-se a gênero, permeiam o social" (PISCITELLI, 2008, p. 263). Procuro, dessa forma, apresentar igualmente algumas ponderações a determinadas características que esse campo nascente tem desenvolvido, especialmente no diálogo anglófono recente entre teóricas dos Estados Unidos e de alguns países da Europa ${ }^{5}$. Devido a este propósito, portanto, ressalto de

3 Essa citação, assim como todas as outras provindas de línguas estrangeiras, serão traduções livres minhas.

4 Adriana Piscitelli (2008), por exemplo, afirma que algumas autoras trabalham também com o termo "categorias de articulação" lembrando que Avtar Brah (2006) tenderia a utilizar a ambas as categorias concomitantemente. Outro termo que costuma ser utilizado por autoras como Patricia Hill Collins (2000) e Wendy Hulko (2009), entre outras, para remeter a questões congêneres é interlocking oppressions, que traduzo por "entrelaçamento de opressões". Porém, em termos gerais utilizarei nesse artigo a categoria "interseccionalidade", uma vez que, entre outras questões, me parece ser a mais disseminada na atualidade. Outra questão digna de nota é que, dentre os trabalhos do referido campo produzidos no Brasil, tendeu-se a utilizar tanto "intersecção" quanto "interseção". O dicionário Houaiss (edição de 2009) afirma que "seção" e "secção" têm o mesmo significado em português, sendo relativas a: "ato ou efeito de secionar(-se); porção retirada de um todo; segmento; ponto ou local onde algo foi cortado ou dividido...", o que indica que não haveria equívoco no uso de nenhuma delas. Contudo, atualmente tenho utilizado a primeira versão, "intersecção".

5 No decorrer do texto tenderei a utilizar "autoras", "pesquisadoras", etc., sempre no feminino, pois, entre outras razões, a franca maioria das contribuições teóricas para o 
antemão que este trabalho não se ocupará de uma revisão do campo latinoamericano ou mesmo brasileiro concernente ao debate, questão que reconheço de suma relevância e complexidade a qual, no entanto, desejo desenvolver a posteriori.

Ademais, a preocupação com a noção de "interseccionalidade" está também diretamente associada à minha formação antropológica. Esta, por sua vez, esteve desde o início influenciada pelos debates teóricos da Antropologia das Relações de Gênero e Sexualidade e, em particular, pela Antropologia Feminista. Tanto em meu mestrado quanto no doutorado preocupei-me com os modos através dos quais marcadores sociais da diferença como gênero, sexualidade, idade/ geração, "raça", classe social e corporalidades interagem, contextual e conjunturalmente, de modo a promover potenciais cenários de desigualdades sociais e hierarquizações. No entanto, tanto na dissertação quanto na tese não pude me ocupar centralmente em apresentar uma revisão sistemática do debate feminista interseccional ${ }^{6}$. Além disso, recordo também de, à época, defrontar-me com dificuldades para encontrar trabalhos que se propusessem a sintetizar tais debates e apresentá-los em revisão. Portanto, tal empreendimento se materializa sucinta e modestamente neste artigo e se propõe a contribuir com interessadas(os) em se aproximar e se inteirar dessas discussões.

debate interseccional é desenvolvida por pesquisadoras. Entretanto, espero que os demais pesquisadores que produzem reflexões na área de estudos feministas interseccionais sintamse também inclusos no termo.

6 Minha tese - desenvolvida no PPGAS/Unicamp sob a orientação da Profa. Dra. Guita Grin Debert - se intitula: "Paizões, Tiozões, Tias e Cacuras: Envelhecimento, meia idade, velhice e homoerotismo masculino na cidade de São Paulo" (HENNING, 2014). Já meu mestrado - realizado no âmbito do PPGAS/UFSC sob a orientação da Profa. Dra. Sonia Weidner Maluf - resultou na dissertação intitulada: "As Diferenças na Diferença: hierarquia e interseções de geração, gênero, classe, raça e corporalidade em bares e boates GLS de Florianópolis, SC" (HENNING, 2008a). Em ambos os trabalhos, embora obviamente com distintos enfoques e campos empíricos, a preocupação acerca do debate interseccional à luz de teorizações feministas foi uma constante. 
Há alguns anos, ao participar de um curso que endereçava debates interseccionais contemporâneos, pude perceber o quanto a "interseccionalidade" estava difundida e como produzia um grande interesse inclusive para pesquisadoras(es) de fora dos estudos feministas e de gênero. Além disso, era possível perceber também que produzia inúmeros questionamentos, dúvidas e confusões, e que se configurava, sobretudo, em uma noção que alcançou centralidade no pensamento feminista nas últimas décadas ${ }^{7}$. Uma das autoras desse campo, Leslie McCall (2005, p. 1771), por exemplo, chega a afirmar que a interseccionalidade poderia ser considerada como uma das mais importantes contribuições teóricas que os estudos de mulheres, conjuntamente com outros campos afins, produziram até o momento. “Todo mundo está falando sobre interseccionalidade, e é certamente uma idéia em processo de florescimento", afirmam Ann Phoenix e Pamela Pattynama (2006). Apesar dessa atenção crescente os distintos usos da noção, o levantamento histórico de seu percurso teórico, assim como suas distintas vertentes parecem ainda ser pouco explorados em termos de análises e teorizações sociais. Sendo assim, pode-se afirmar que um desenvolvimento e diálogo transnacional nas últimas décadas têm marcado as análises interseccionais a partir, principalmente (mas não apenas) de teóricas feministas e dos estudos de gênero baseadas nos Estados Unidos e em alguns países europeus. No entanto, é importante pontuar que esse desenvolvimento não pressupõe, de modo algum, coesão nos olhares teóricos, uma vez que há uma vigorosa e acalorada profusão de visões contemporâneas acerca da noção, a qual tende a ser vista, por exemplo, como teoria,

O curso a que me refiro é a edição de 2009 do Fábrica de Ideias, promovido pelo CEAO/UFBA, tendo como tema geral "Corpo, Poder e Identidade" e realizado entre os dias 03 e 21 de agosto. Nesse curso, felizmente pude assistir às aulas de professoras como a lendária Angela Davis, assim como Gina Dent, Mara Viveros Vigoya e vários(as) outros(as) professores(as). Alguns dos módulos do evento, assim como alguns debates e o contato extremamente frutífero com diversos dos cursistas peruanos, colombianos, brasileiros e de várias outras nacionalidades, foram muito inspiradores para parte dos debates aqui presentes. 
método, abordagem, paradigma, conceito, preocupação heurística, "lente de análise social", base de trabalho analítico, metáfora analítica, etc. (Davis, 2008, p. 68; Hulko, 2009, p. 44).

Levando em consideração essa profusão de olhares teóricos e conceituais, neste artigo apresento primeiramente algumas visões sobre o contexto de formação do debate interseccional nos Estados Unidos e no Reino Unido ${ }^{8}$, e, a seguir, estabeleço as principais vertentes de trabalho vigentes atualmente. Para traçar esses olhares embaso-me principalmente em um levantamento bibliográfico de algumas dezenas de textos, a maior parte artigos e ensaios, publicados nos últimos anos nos EUA e na Europa, mas também (embora em menor expressão) por teóricas da América Latina e de outros países. A atenção se volta para algumas das possíveis contribuições que a análise interseccional oferece ao pensamento feminista e à teoria social como um todo, assim como a pontos prementes que atravessam o campo e geram questionamentos ainda em aberto.

\section{CONTEXTUALIZANDO A EMERGÊNCIA dA PREOCUPAÇÃo INTERSECCIONAL}

Embora o termo "interseccionalidade" tenha sido cunhado apenas em 1989 pela teórica feminista estadunidense Kimberlé Crenshaw (1991)9, a preocupação em entrelaçar distintas formas de diferenciações sociais (e de desigualdades) é bem anterior, e um de seus marcos simbólicos tem sido visto como as contribuições do influente manifesto de 1977 do Combahee River Collective $^{10}$. Tratava-se de um coletivo de feministas negras e lésbicas baseado

\footnotetext{
8 Embora naquele momento o termo "interseccionalidade", obviamente, ainda não tivesse sido criado.

9 É importante postular que há distintos desenvolvimentos no modo como Crenshaw (1991) reflete e propõe a noção de "interseccionalidade". Em seus primeiros escritos a autora via a interseccionalidade como uma "metáfora" e em seus textos posteriores ela passou a apontá-la como uma "categoria provisória".

10 O manifesto postulava, em termos concisos: a) a experiência combinada de entrelaçamento de opressões por sexo, raça, classe, sexualidade e a necessidade de desenvolvimento de uma análise e prática baseadas no fato de que as formas de opressão estão entrelaçadas;
} 
em Boston, entre 1973 e 1980, o qual defendia uma luta articulada não apenas contra a opressão sexual das mulheres, mas também contra outras formas de dominação e de desigualdades baseadas em racismos, heterossexismos e exploração por classe social (BASSEL, 2010; LEWIS, 2009; HULKO, 2009; VIVEROS VIGOYA, 2008; DAVIS, 2008; DENIS, 2008; BRAH, 2006, 2007; VERLOO, 2006; KNAPP, 2005; BREWER, 2005; BRAH E PHOENIX, 2004; ZERAI, 2000, etc. $)^{11}$.

Contudo, Avtar Brah e Ann Phoenix (2004, pp. 76-77), assim como em BRAH (2007, p. 249), apontam para um processo bem mais antigo de preocupação feminista com formas de entrelaçamento de diferenças na produção de desigualdades sociais. Referem-se ao movimento feminista abolicionista nos Estados Unidos de meados do século XIX, parte dos "feminismos de primeira onda":

Nos EUA as tensões políticas no feminismo envolvendo as inter-relações entre 'raça' e outros fatores como classe e gênero datam das campanhas anti-escravidão. Durante a década de 1830, por exemplo, as mulheres estadunidenses se tornaram cada vez mais ativas no movimento abolicionista, contexto no qual aprenderam a defender seus próprios direitos de se envolver no trabalho político e onde suas experiências de relativa marginalização as compeliram a formar sociedades de mulheres anti-escravagistas separadas [das sociedades anti-escravagistas de homens]. A primeira sociedade feminina anti-escravagista foi formada

\footnotetext{
b) a centralidade da luta pela liberação das mulheres negras e que para que essa liberação se efetivasse era necessária a luta conjunta contra opressões sexistas, racistas, de classe e de sexualidade; c) a consideração da importância do Feminismo Negro como movimento político para combater as opressões simultâneas das "mulheres de cor" (women of color); d) a necessidade da destruição do capitalismo, do imperialismo e do patriarcado, e por fim, e) denunciar o racismo no movimento feminista de mulheres brancas (COMBAHEE RIVER COLECTIVE, 1982 [1977]).

11 Entretanto, entre essas autoras, há uma considerável variação na interpretação do papel que atribuem ao manifesto e atuação do Combahee River Collective na alteração da agenda dos movimentos feministas de fins de 1970 e durante a década de 1980. Entre as que atribuem um papel de destaque em suas análises estão: Hulko, 2009; Viveros Vigoya, 2008; Davis, 2008; Denis, 2008; Brah, 2006, 2007; Knapp, 2005; Brewer, 2005; Brah e Phoenix, 2004, etc.
} 
em 1832 por mulheres negras de Salem, Massachusetts, seguidas por sociedades similares estabelecidas por mulheres brancas de outros locais (BRAH, 2007, p. 249).

Para contextualizar esse momento prévio, Brah e Phoenix (2004, p. 76-77) apresentam a personagem histórica Sojourner Truth, mulher afro-americana que foi escravizada e ficou conhecida por sua fala proferida em 1851, na Convenção dos Direitos das Mulheres, em Akron, Ohio. De acordo com as autoras, o discurso de Truth refletiria a complexidade da posição da qual falava, no caso, entre as bandeiras anti-escravidão dos negros do Sul dos Estados Unidos e das reinvindicações nascentes das mulheres (brancas) do Norte. Nesse caso, considerando o contexto histórico-cultural do século XIX em que importantes lutas sociais - em prol do voto das mulheres, de liberdades individuais, da luta pelo fim da escravidão - estariam emersas ${ }^{12}$. Truth, refletindo sobre o conjunto articulado de desigualdades que a afetavam, assim como a outras mulheres negras, se pergunta:

Aquele homem lá diz que uma mulher precisa ser ajudada ao entrar em carruagens, e levantada sobre as valas, e ficar nos melhores lugares onde quer que vá. Ninguém me ajuda em lugar nenhum! E eu não sou uma mulher? Olhem para mim! Olhem para o meu braço. Eu arei, eu plantei e eu recolhi tudo para os celeiros. E nenhum homem pode me auxiliar. E eu não sou uma mulher? Eu poderia trabalhar tanto e comer tanto quanto qualquer homem (...) e suportar o chicote tão bem quanto! E eu não sou uma mulher? Eu dei à luz a crianças e vi a maior parte delas ser vendida

12 Patrícia Hill Collins (2000, pp. 01-03), por sua vez, apresenta outra personagem histórica dos feminismos negros de "primeira onda" nos Estados Unidos. Trata-se de Maria W. Stewart, afro-americana que, na década de 1830, foi a primeira mulher a fazer falas políticas em público e cujos textos deixaram registros para a posterioridade. Ela abordou uma variedade de temas que seriam tomados por suas sucessoras nos feminismos negros. Hill Collins afirma que certamente existiram muitas outras "Maria Stewart" cujas contribuições intelectuais e ativistas foram suprimidas pelos contextos sociais e históricos de silenciamento e "subordinação das mulheres negras". 
como escravas. E quando eu chorei com o sofrimento de uma mãe, ninguém além de Jesus me ouviu. E eu não sou uma mulher? (BRAH \& PHOENIX, 2004, p. 77).

A partir da forte, instigante e representativa fala de Sojourner Truth, BrahePhoenix (2004)afirmam quenãoapenas várias das questões que versam sobre entrelaçamento de diferenças e desigualdades e que (re)emergiram a partir da década de 1970 já estavam presentes nessa fala de mais de um século, como também o próprio debate ocorrido durante as décadas de 1980 e 1990 acerca da crítica ao essencialismo contido na categoria "mulheres" (como, por exemplo, em BUTLER, 2003) já estaria, de certo modo, interessantemente ali contida.

Essa é uma relevante historicização do "pensamento interseccional" feita por Brah e Phoenix (2004) ${ }^{13}$, remetendo a debates bem anteriores às proposições dos Black Feminisms dos anos 1970, a qual não é muito usual no campo abordado. Por sua vez, Patricia Hill Collins (2000, p. 03) afirma que houve historicamente "descontinuidades na tradição do pensamento das mulheres afro-americanas", que às vezes tiveram suas vozes ouvidas mais expressivamente e em outros momentos tenderam a ser silenciadas ${ }^{14}$.

Como afirmado anteriormente, vê-se um retorno do debate sobre a experiência de entrecruzamento de diferenciações sociais com grande fôlego a partir de fins de 1970, e quanto à contextualização histórica desse novo momento de assunção da preocupação interseccional, Rose Brewer (2005) afirma que o Combahee River Collective deu o tom do debate dos feminismos radicais negros do

\footnotetext{
13 Levando obviamente em consideração que naquele momento o debate não se estabelecia à maneira contemporânea e, como dito anteriormente, não se operasse com a categoria "interseccionalidade".

14 É importante ressaltar que autoras dos feminismos chicanos foram bastante importantes nesses debates interseccionais, como, por exemplo, Gloria Anzaldua e Cherrie Moraga, assim como teóricas de origem asiática como Trinh T. Minh-ha.
} 
período e influenciou marcantemente as feministas acadêmicas a partir de um contexto ativista extra-acadêmico ${ }^{15}$.

Já Avtar Brah (2007, p. 250) faz também um contraponto ao contexto estadunidenseapresentandoo papel-chavequeosFeminismos Negros Britânicos possuíram no debate interseccional ${ }^{16}$, com, por exemplo, sua participação pessoal na criação, em 1978, na Inglaterra da OWAAD, Organization of Women of African and Asian Descent, algo como "Organização de Mulheres de Ascendência Africana e Asiática", entidade que promovia desde seu início discussões sobre a experiência articulada de classe social, raça, gênero e diferenças culturais na vida de mulheres "não-brancas". Afirma então que nesse momento histórico havia um número significativo de publicações dos feminismos de segunda onda que mostravam certo descaso com o racismo como uma característica interna das "relações patriarcais ocidentais". Esse tipo de negligência gerava respostas críticas de mulheres anti-racistas, especialmente "mulheres de cor" (women of color), sendo que uma das primeiras críticas no contexto anglófono foi produzida pelo Combahee River Collective $(1977)^{17}$.

15 “No início dos 1970's, o Coletivo estava sendo construído e dava a partida para o agora fundamental manifesto do Combahee River Collective que afirmava, como ativistas feministas negras e lésbicas, que as opressões estavam inextricavelmente conectadas na vida de mulheres negras, [ou seja,] a interseccionalidade de raça, classe, gênero e sexualidade. Alguns assassinatos (...) as inspiraram para a ação imperativa (...) treze mulheres negras haviam sido assassinadas em Boston e pouco havia sido feito. Suas vidas estavam sendo invisibilizadas por ativistas negros homens e por feministas brancas. O Combahee River Collective organizado exigiu ação e reconfigurou, de fora, a academia através da escrita de um documento fundamental saído das lutas" (BREWER, 2005, p. 355).

16 Considerando-se que, segundo Brah (2007) no Reino Unido houve a coalização de todas as mulheres "não-brancas" na insígnia dos "Feminismos Negros".

17 Sylvanna M. Falcón (2009, p. 467), também sobre esse momento, afirma que: “As mulheres de cor criticavam os movimentos feminista e dos direitos civis dos anos 1960 e 1970 por não trabalharem com as temáticas de raça e gênero respectivamente. As ativistas mulheres de cor dessa época eram frequentemente forçadas a optar por um dos lados entre as lutas feministas e as dos direitos civis. Fazer a escolha era difícil para mulheres de cor porque suas experiências não eram apenas baseadas em raça ou gênero, mas em raça $e$ gênero. Frustradas com feministas brancas que fracassaram em integrar o anti-racismo em seu ativismo e com homens de cor que fracassaram na luta contra seu sexismo, as mulheres de cor começaram a se organizar e vocalizar suas questões [específicas]." 
No entanto, deste cenário de debates, creio que é importante apontar, dentre outras questões, que essas relevantes formulações de preocupações sobre articulações de diferenças nos anos 1970 provinham de campos não necessariamente - e apenas - acadêmicos, mas também, e marcantemente, de coletivos de ativistas feministas negras e lésbicas. É problemático constatar que poucas teóricas do que poderia ser chamado atualmente de "campo feminista de estudos interseccionais" considerem a importância do manifesto e das atuações políticas desse e de outros coletivos como um marco relevante para o pensamento que procura compreender o entrelaçamento de marcas de diferença na construção (ou não) de desigualdades. E é também digno de nota que uma parte dos trabalhos contemporâneos tende, de distintas formas, a secundarizar, ou simplesmente a ignorar, o papel dos Black Feminisms no novo impulso fundador da reflexão interseccional nos anos 1970 (e inclusive em suas expressões nos feminismos de primeira onda).

Retornando, todavia, ao processo de contextualização histórica da formação do campo interseccional, na primeira metade da década de 1980, refletindo tais debates de ativistas e acadêmicas, Angela Davis (1981) e bell hooks (1981) publicam, respectivamente, Women, Race and Class, e Ain't I a Woman? Black Women and Feminism, ambas apresentando suas contribuições e críticas acerca da problemática da estabilidade homogeneizante da categoria "mulher" e a necessidade de se atentar igualmente às formas combinadas de diferenciações e desigualdades como "raça" e classe social, entrecortando as experiências de mulheres ${ }^{18}$. A elas se seguiram publicações de Audrey

18 Para contextualizar parcialmente o debate feminista em fins da década de 1970, trago algumas formulações da antropóloga feminista Michelle Rosaldo (1995). A autora propunha, para fins de explicar a "assimetria sexual", a distinção público $x$ doméstico (questão historicamente bastante relevante no debate feminista) que seria derivada do fato de as mulheres engravidarem, gestarem, terem o parto e necessitarem amamentar, o que as manteria ocupadas com a criação da prole e afastadas do âmbito das atividades públicas, de poder e atuação, assim como de controle e regulação social, o qual acabava sendo tomado 
Lorde (1984) e Patricia Hill Collins (2000[1990]), cujas preocupações teóricas também envolviam as formas de entrelaçamento de diferenças sociais ${ }^{19}$. Na sequência, no decorrer da década de 1980, várias outras autoras feministas, de diversos campos disciplinares, começaram igualmente a publicar importantes trabalhos críticos sobre gênero, como Joan Scott (1988), Marilyn Strathern (1988), Donna Haraway (1991) e Judith Butler (2003[1990]), sendo que algumas delas também formulavam acerca da temática das articulações de diferenças, auxiliando a produzir "deslocamentos nos paradigmas disciplinares no marco dos quais trabalhavam" (PISCITELLI, 2008). A teórica pós-estruturalista Judith Butler, por exemplo, em sua empreitada em problematizar a categoria "mulher" como sujeito do feminismo afirma que:

se alguém 'é' uma mulher, isso certamente não é tudo o que esse alguém é (...) o gênero estabelece interseções com modalidades raciais, classistas, étnicas, sexuais e regionais de identidades discursivamente constituídas (...) [e] se tornou impossível separar a noção de 'gênero' das interseções políticas e culturais em que invariavelmente ela é produzida e mantida (BUTLER, 2003, p. 20).

Entretanto, conforme Adriana Piscitelli (2008, p. 266) e Regina Facchini (2008, pp. 91-94) apontam, Butler tende a manter o enfoque

pelos homens, livres das imposições "naturais e biológicas" relegadas às mulheres. Rosaldo criticava a procura por uma origem universal para a assimetria sexual, posto que isto ignoraria as especificidades culturais de cada sociedade e, portanto, não auxiliaria na compreensão das manifestações peculiares que tal assimetria desenvolveria em cada cultura. Para ela, não era possível transculturalizar a opressão sexual. Procurava, em 1980, e apesar de explicar a assimetria através de uma determinação biológica (a gravidez, a amamentação e o cuidado com os filhos) estabelecer uma conceituação de gênero desvinculada de parâmetros biológicos: "Gênero, em todos os grupos humanos, deve então ser entendido em termos políticos e sociais com referência não a limitações biológicas, mas sim às formas locais e específicas de relações sociais e particularmente de desigualdade social" (ROSALDO, 1995, p. 22).

19 Sobre as contribuições teóricas de acadêmicas afro-americanas ou "africana scholars", consultar Assata Zerai (2000). Quanto às dificuldades enfrentadas pelas intelectuais negras no meio acadêmico, assim como sobre a necessidade de também se frisar o prazer e alegria a elas proporcionadas pelo trabalho intelectual, consultar bell hooks (1995). 
central de suas reflexões na articulação das categorias de gênero e sexualidade, o que se poderia observar mesmo em sua acepção de "abjeção", marcada pela inter-relação entre tais categorias ${ }^{20}$. Assim, ao mesmo tempo que nos anos 1980 uma crítica à estabilidade da categoria "mulher" se desenvolvia, apontando as diferenças sociais que a recortavam, também se estabelecia uma crítica ao conceito de gênero, tal como fora pensado até então ${ }^{21}$.

Voltando, porém, à questão das formas pelas quais as autoras tendiam a trabalhar com a interseccionalidade, em alguns casos a tendência foi a de se reforçar certos cruzamentos de marcadores de diferença em detrimento de outros que se tornavam secundarizados (como o reforço na tríade, quase "mantra": raça, classe e gênero), ou, então, frisar a preeminência de um marcador sobre os demais, seja, por exemplo, classe social em relação à "raça" e gênero no caso de algumas correntes marxistas.

Nira Yuval-Davis (2006, pp. 200-201) chama atenção, porém, para o fato de que a "base ontológica" de cada uma dessas divisões marcando diferenças tende a ter certa autonomia e a priorizar esferas

20 Facchini (2008, p. 92) faz um interessante questionamento quanto à limitação que tal articulação preferencial de "gênero" e "sexualidade" pode gerar em relação aos usos da noção butleriana de "abjeção", perguntando-se: "em que medida essa priorização da crítica a um imperativo heterossexual não limita o alcance das proposições de Butler a respeito dos 'corpos abjetos'? Por que, necessariamente, a abjeção deve ser pensada em termos da heterossexualidade compulsória ou da matriz heterossexual? Como a abjeção sexual se constitui a partir de outros campos de poder estruturados em esferas analíticas separadas que, segundo a própria autora, 'não podem se constituir umas sem as outras'? (BUTLER, 2002, p. 242)".

21 De acordo com Piscitelli (2008, p. 264): "a partir da segunda metade da década de 1970, o conceito de gênero, pensado como construção arbitrária, variável, de aspectos vinculados ao sexo biológico, tido como natural e imutável, tinha se difundido de maneira extraordinária. Esse conceito, pensado no marco da distinção entre sexo e gênero, era considerado como um avanço em relação à categoria mulher (PISCITELLI, 2002). Os escritos críticos de finais da década de 1980, porém, questionaram os pressupostos presentes na distinção sexo/ gênero. Um dos motivos foi a fixidez e unidade que essa distinção conferia às identidades de gênero, ao formular a existência de uma base biológica imutável que dividia a humanidade em dois gêneros. Outros dos aspectos problematizados foi a universalidade atribuída a essa distinção" (PISCITELLI, 2008, p. 264). Para mais referências a respeito do debate conceitual acerca de "gênero", consultar Piscitelli (1998) e Henning (2008b). 
diferentes das relações sociais, um cuidado para não afirmar, por exemplo, que classe social é "a mesma coisa" que gênero ou raça ${ }^{22}$. Contudo, para além de se enfocar ou reforçar a importância primeira de um marcador de diferença (ou da interação entre marcadores determinados) em detrimento de outros, é de suma importância citar aqui uma relevante característica que o campo feminista de estudos interseccionais estaria moldando no contemporâneo:

A proposta de trabalho com essas categorias [interseccionalidade, categorias de articulação] é oferecer ferramentas analíticas para apreender a articulação de múltiplas diferenças e desigualdades. É importante destacar que já não se trata da diferença sexual, nem da relação entre gênero e raça ou gênero e sexualidade, mas da diferença, em sentido amplo, para dar cabida às interações entre possíveis diferenças em contextos específicos (PISCITELLI, 2008, p. 266).

Deste modo, entre outras questões, um notável giro é o deslocamento da obrigatoriedade de partir de um marcador específico para desenvolver a análise interseccional, para uma atenção localizada às configurações de diferenciações sociais e de possíveis desigualdades em termos contextualizados histórica e culturalmente. Tal giro, portanto, relativizaria o aspecto indispensável de, por exemplo, se recitar o "mantra dos três marcadores", uma vez que se opõe à ideia de partir de diferenças tidas como relevantes a priori, assim como se opõe à necessidade de criação de uma ampla, generalizante e transcultural "teoria interseccional estrutural", ao primar por análises localizadas e contingenciais. Auxiliaria também a responder a uma das questões vistas como uma espécie de "calcanhar de Aquiles" desse campo: o seu pretenso caráter de infinita proliferação de diferenciações possíveis ou

22 Knapp $(2005$, p. 81) afirma que a teoria interseccional tendeu historicamente a ignorar as ontologias específicas e as histórias localizadas social e culturalmente de cada categoria de diferença e desigualdade social. 
o que chamo de as "Olimpíadas das Diferenças" 23 . Essa ênfase ressaltaria, assim, a possibilidade de certa contenção analítica, contestando o assim visto - necessário "caráter de abertura ilimitada" do campo interseccional. Portanto, não necessariamente é preciso desenvolver a análise de uma infinidade de marcadores em toda e qualquer análise social, mas atentar para o entrelaçamento daqueles que se mostram relevantes contextualmente, ou seja, partindo de análises atentas às diferenças que fazem diferença em termos específicos, históricos, localizados e, obviamente, políticos.

Sendo assim, após apresentar alguns dos aspectos do percurso histórico da noção de interseccionalidade, debato a seguir suas principais vertentes contemporâneas, assim como outras discussões, polêmicas e questões gerais que recortam o campo atual.

\section{As DISTINTAS ABORDAGENS INTERSECCIONAIS}

A filósofa Baukje Prins (2006, p. 279) apresenta duas principais vertentes entre as teóricas que trabalham com interseccionalidades, vertentes estas estabelecidas a partir principalmente de distintas concepções de poder, agência e estrutura/sistema. Para a autora, essas vertentes seriam marcadas, de um lado, por uma abordagem sistêmical estrutural localizada basicamente nos Estados Unidos e que daria mais atenção aos impactos do sistema ou estrutura sobre a formação de identidades. Essa abordagem seria representada, por exemplo, pelos trabalhos de autoras como Kimberlé Crenshaw (1991) e Patricia Hill

23 Aqui me inspiro livremente em Hancock (2007) quando a autora cita a crítica às "oppression olympics" ou "Olimpíadas das Opressões", ou seja, uma competição entre grupos marginais por migalhas de recursos (estatais, de ONG's, etc.), ao invés da cooperação mútua para alterar toda a lógica de redistribuição de recursos. A autora está se referindo a questões sensivelmente distintas das que procuro frisar, como procuro deixar explícito no texto. 
Collins (2000[1990]). E, por outro lado, uma abordagem construcionista - encampada principalmente por acadêmicas do Reino Unido, como Anne McKlinctock (1995) e Avtar Brah $(2004 ; 2007)^{24}$ - a qual tenderia a desenvolver uma concepção de poder mais dinâmica e relacional, levando em consideração aspectos de agência e identidade social ${ }^{25}$.

Para a abordagem sistêmicalestrutural, a tendência, em termos gerais, é conceituar gênero, "raça" e classe como sistemas de dominação, opressão e marginalização que determinam ou estruturam a formação de identidades (PRINS, 2006, p. 279). A historiadora colombiana Mara Viveros Vigoya (2008, p. 06), por exemplo, contextualiza o pensamento de Crenshaw (2005) afirmando que para essa autora a "interseccionalidade é inerente a toda relação de dominação e que, como estrutura de dominação, impede ou debilita as tentativas de resistência" 26 .

As principais críticas que essa abordagem recebe, segundo Prins (2006, pp. 278-282) são: destacar excessivamente o impacto do sistema ou da estrutura sobre a formação de identidades; tratar o poder como uma propriedade de alguns em detrimento de outros e não como uma relação (fazendo um uso seletivo de Foucault, uma vez que reforçaria apenas os efeitos repressivos do poder, ignorando

24 Avtar Brah (2007, pp. 253-255) trabalha com a ideia de diferença a partir de quatro eixos que se entrecruzam e se inter-relacionam: a) diferença teorizada como relação social em sentido sociológico; b) explorada em termos de experiência humana; c) entendida como subjetividade; d) e analisada em termos de identidade social. Esses eixos, por exemplo, a auxiliam a trabalhar de forma bastante interessante com o conceito de identidade pós-estruturalista (como descentrada, fragmentada e em processo), porém em termos de diferença entendida como subjetividade, ao mesmo tempo em que isso não se aplicaria quanto à idéia de diferença como identidade social e política em termos de ação política consciente (mesmo considerando que a ação consciente é sempre marcada por investimentos emocionais interiores, rupturas e contradições). Com isso, Brah, entre outras questões, procura contestar as visões de que a concepção pós-estruturalista de identidade não proporcionaria uma base para a ação política.

25 Essa divisão EUA - Reino Unido precisa ser posta em suspensão, uma vez que autoras de diversas outras nacionalidades têm aproximações e distanciamentos em relação a cada abordagem, assim como, autoras de ambos os países podem não se encaixar na divisão em termos nacionais proposta por Prins (2006).

26 O efeito itálico nessa citação é meu. 
sua faceta produtiva na formação de subjetividades, assim como relações de poder marcadas por conflitos e pontos de resistência); e, por fim, os sujeitos aparecem constituídos por sistemas de dominação, subordinação, marginalização e carentes de agência.

Adriana Piscitelli (2008, pp. 267-269) afirma, por sua vez, que além das limitações supracitadas haveria outra, bastante significativa, nessa abordagem: segundo uma perspectiva antropológica, a vertente sistêmica fundiria a idéia de diferença à de desigualdade, questão problemática, uma vez que tal associação a priori e imperativa não poderia ser considerada como condição primária (e sinequa non) em todo e qualquer contexto cultural e histórico. Nessa direção - e chamando a atenção para um fator que creio ser um cuidado imprescindível para o campo feminista interseccional atual - a autora pondera que, "como a diferença nem sempre é um marcador de hierarquia nem de opressão, uma pergunta a ser constantemente feita é se a diferença remete à desigualdade, opressão, exploração. Ou, ao contrário, se a diferença remete a igualitarismo, diversidade, ou a formas democráticas de agência política" (PISCITELLI, 2008, p. 269).

$\mathrm{Na}$ abordagem construcionista, portanto, haveria "distinções entre categorias de diferenciação e sistemas de discriminação, entre diferença e desigualdade" (PISCITELLI, 2008, p. 268). A vertente construcionista estaria marcada também por uma visão de poder vinculada, em termos gerais, a Gramsci, em uma perspectiva de embates constantes em torno da hegemonia. E nessa vertente seríamos considerados, ao mesmo tempo, "autores e co-autores de nossas vidas" (PRINS, 2006).

Alternativamente a uma perspectiva aditiva de "opressões" (as metáforas aritméticas são uma tendência da vertente sistêmica), na vertente construcionista, "raça", gênero e classe não são vistos como facetas que existem em isolamento umas das outras, o caráter de articulação seria propriamente constitutivo das categorias, assim como 
da relação de umas com as outras. Dessa forma, tais categorias "não são idênticas entre si, mas existem em relações íntimas, recíprocas e contraditórias" (PISCITELLI, 2008, p. 268). Trata-se de uma vertente que, obviamente, aborda os efeitos coercitivos das relações de poder através das interseccionalidades, mas ao mesmo tempo preocupase com os pontos de fuga, de resistência e agência que práticas interseccionais igualmente podem produzir ${ }^{27}$.

No entanto, para além da mera polarização entre abordagem sistêmico-estrutural versus abordagem construcionista, Sylvia Walby (2007, pp. 451-453) complexifica as vertentes interseccionais ao apresentar - partindo daquelas propostas por Prins - outras cinco abordagens difundidas que nos permitem um vislumbre da crescente complexidade das teorizações do campo feminista interseccional: 1) uma abordagem mais geral de crítica às super-generalizações que tende atualmente a ser consenso entre teóricas feministas; 2) um reducionismo a um único eixo primário de desigualdade estando outros eixos subordinados ao primário (consubstanciado, por exemplo, nas frases: "classe é o que realmente importa" ou "gênero é o marcador abrangente que está acima de todos os outros", etc.); 3) um microreducionismo ou a rejeição da conceituação das relações sociais em termos de sistemas. A partir dessa rejeição, segue-se uma estratégia de descobrir categorias interseccionais negligenciadas (a autora, por sua vez, criticaria a suposta incapacidade dessa abordagem de refletir sobre questões mais amplas como as de "horizontes globais"); 4) a rejeição das categorias de conjunto, sendo que nessa abordagem as categorias são vistas como inadequadas nas representações do mundo como é vivido e como provocadoras da perda da experiência das práticas. $\mathrm{O}$

\footnotetext{
“Os processos mediante os quais os indivíduos se tornam sujeitos não significam apenas que alguém será sujeito a um poder soberano, mas há algo mais, que oferece possibilidades para o sujeito. E os marcadores de identidade, como gênero, classe ou etnicidade não aparecem apenas como formas de categorizações exclusivamente limitantes. Eles oferecem, simultaneamente, recursos que possibilitam a ação" (PISCITELLI, 2008, p. 268).
} 
foco na diferença é privilegiado em relação ao foco nas identidades. Para a autora, tal "desconstrucionismo radical" acaba por requerer, em um plano analítico, distinções entre categorias; 5) no reducionismo segregacionário, ao invés de se negar as categorias, a estratégia é construir uma análise aperfeiçoada de cada marca de diferença como parte do processo de analisar suas intersecções. Nessa abordagem estabelece-se a irredutibilidade de uma categoria à outra e a base ontológica de cada divisão é vista como autônoma e priorizadora de esferas distintas das relações sociais.

A crítica da autora a essa abordagem é que ocorreria uma segregação redutora de cada categoria. Ou seja, classe estaria relegada apenas à economia, gênero ao que a autora chamou de "discurso sobre a diferença sexual", assim como etnia e raça a outros âmbitos específicos. Tal abordagem omitiria as formas em que uma categoria social marca, afeta e altera os significados de outra. Em outras palavras, omitiria-se como gênero pode ser racializado, como raça pode estar sexualizada, a classe generificada, geração/idade sexualizadas, etc. Apresentar essas cinco tendências de abordagens nos estudos feministas interseccionais contemporâneos - embora não as possamos desenvolver em minúcia nesse momento - auxilia-nos a vislumbrar a crescente complexidade, assim como a reflexividade crítica, as quais têm atravessado expressivamente o campo em questão.

Pensando, porém, em termos de agência e interseccionalidade - espaço aberto e incentivado pela abordagem que Prins chamaria de "construcionista" - Brendy Boogaard e Conny Roggeband (2010, pp. 54-55), em sua análise dos paradoxos que cruzam as configurações de diferença e desigualdade entre membros da Força Policial Holandesa, afirmam que a literatura interseccional tendeu historicamente a privilegiar as dimensões estruturais das configurações sociais de desigualdade e, considerando tal fator, propõem uma leitura de "estrutura" como igualmente produtora de "recursos" para a ação: 
"Levar em consideração ambos os lados, o estrutural e o da agência, na análise interseccional permite uma compreensão mais processual e dinâmica das produções de desigualdades".

Segundo elas, os indivíduos abordados em suas pesquisas podiam estar em desvantagem em relação a alguma de suas marcas identitárias (por exemplo, gênero ou identidade étnica), porém tendiam a manipular a vantagem que possuíam em relação a outros traços identitários, questão que os auxiliava a superar conjunturalmente determinadas desigualdades. Por outro lado, ressaltam as autoras, a sobressalência de certas marcas identitárias socialmente mais positivas geralmente contribuía para reproduzir desigualdades relacionadas a outras marcas identitárias. Contudo, o que procuram deixar em relevo é que as categorias entrelaçadas podem resultar tanto em experiências de desigualdades sociais, quanto em oportunidades que representam muito mais que a simples soma de suas partes ${ }^{28}$.

Em minhas pesquisas etnográficas no mestrado e no doutorado pude investigar algumas correlações interessantes quanto aos dados dessas autoras. Analisando o entrelaçamento de marcadores sociais de diferença (sexualidade, idade/geração, gênero, "raça", classe social e corporalidades) em espaços de sociabilidades homoeróticas como bares, boates, espaços públicos e em redes de sociabilidade específicas na cidade de Florianópolis, SC (e mais recentemente em interações sociais mediadas pela internet entre homens com práticas sexuais homoeróticas na meia idade ou mais velhos e residentes na cidade de São Paulo, SP), tenho analisado formas de (des)qualificação de

28 Mara Viveros Vigoya (2008), analisando os estudos interseccionais latino-americanos (no caso, um levantamento da bibliografia que inter-relaciona gênero, sexualidade e raça), afirma que há duas principais perspectivas que estão espraiadas na região: a) uma perspectiva foucaultiana, envolvendo principalmente seu conceito de biopoder e revisada por teorias pós-coloniais e subalternas, e b) uma perspectiva de orientação feminista (dos Black Feminisms e teorias de interseccionalidade). Afirma também que há três eixos temáticos mais expressivos nos estudos interseccionais latino-americanos: I) um enfoque nas inter-relações entre mestiçagem, nação, raça e sexualidade; II) sexualidade e desejo em contextos racializados; e III) multiculturalismo e sexualidade racializada. 
diferenças, porém também formas não desprezíveis do que proponho chamar de "agência interseccional". Ou seja, espaços de ação calcados em marcadores sociais da diferença e que se dão em resposta aos cenários potenciais de desigualdades com as quais os sujeitos se confrontam.

O cuidado mais amplo que várias autoras ressaltam, porém, e que pude constatar em minha revisão, é o de evitar uma análise engessada no âmbito de estruturas absolutas que condicionariam identidades e subjetividades, criando sujeitos meramente subalternos, submetidos, invisibilizados, silenciados e desempoderados. É importante ressaltar, no entanto, que obviamente nem todos os sujeitos estabelecem táticas agenciais sempre bem sucedidas, assim como não se propõe aqui, de modo algum, que se ignore ou se secundarize, $a$ priori, o impacto das estruturas sociais na formação de identidades, subjetividades e na própria capacidade de agência. O que se põe em primeiro plano é a relevância de se atentar igualmente para possíveis formas táticas de agência interseccional - algo que, virtualmente, ainda está em larga medida secundarizado ou mesmo apagado no campo em questão. Em outras palavras, ressalta-se a importância de atentar para os modos os quais os sujeitos potencialmente se utilizam de suas próprias marcas identitárias interseccionais (assim como na relação com os traços identitários interseccionais de outras pessoas) de modo a lidar com a criação, o questionamento e a desconstrução social de desigualdades.

Levando em consideração o conjunto das questões apresentadas até o momento, proponho uma noção de interseccionalidade compreendida primeiramente como relativa às formas de entrelaçamento entre os marcadores sociais da diferença e suas potenciais decorrências em termos de desigualdades sociais, assim como relativa ao desenvolvimento de táticas de resistência, questionamento e desconstrução da desigualdade, sobretudo sob distintas formas de agência interseccional. Reforça-se que a 
interseccionalidade, portanto, precisa ser concebida também a partir de práticas sociais decorrentes da interação conjuntural desses marcadores não apenas em seus efeitos de produção de desigualdades.

Dessa maneira, é preciso frisar que ao mesmo tempo em que a noção de interseccionalidade abre um relevante espaço para análise de contextosespecíficos deconstruçãodediferenciaçõesededesigualdades sociais, ela pode também proporcionar uma contrapartida em termos de um potencial para analisar e por em relevo as ferramentas agenciais para "desfazer", "desmontar" e "desconstruir" possíveis desigualdades. Essa atenção, consequentemente, auxiliaria a evitar o risco de uma reificação da "produção" e "construção" da diferença, vista como sinônimo de desigualdade, e a frisar a potencialidade "igualitarista" que o conceito pode prover em termos de práticas sociais no campo de distintas formas de agência interseccional.

INTERSECCIONALIDADE, PRIVILÉgios, FLUXOS DE TEORIZAÇÕES E O “SUL GLOBAL"

Gostaria, por fim, de apresentar algumas breves considerações críticas acerca do estabelecimento de parte do campo contemporâneo de estudos feministas interseccionais nos Estados Unidos e na Europa. Em primeiro lugar é possível perceber uma presença forte, em parte dos estudos, de uma vinculação da ideia de interseccionalidade a uma aplicação limitada ao âmbito das "mulheres", apesar de, por exemplo, já existirem estudos que abordem masculinidades e interseccionalidades (MIESCHER, 2008), assim como temáticas alternativas ${ }^{29}$.

29 A análise interseccional tem inspirado pesquisas em inúmeras áreas e temáticas, tais como: publicidade (GILL, 2009); movimentos feministas e multiculturalismo (LÉPINARD, 2010); imigração e violência doméstica (EREZ; ADELMAN ; GREGORY, 2009); animais e ecofeminismo (TWINE, 2010); histórias de vida em relação ao conceito de "dialogical self" (BUITELAAR, 2006); cidadania e múltiplas noções de pertencimento (belonging) (CHRISTENSEN, 2009); pesquisa de campo (MAZZEI \& O’BRIEN, 2009); narrativas e experiências de vida de "mulheres de cor" (women of color) como educadoras em trabalhos 
Ainda dentro dessa perspectiva vinculada apenas às "mulheres", é interessante perceber que o "objeto" privilegiado da análise interseccional desse campo são as mulheres, digamos, "subalternizadas", o que, obviamente, não se trata de um "problema" em si. No entanto, esse friso, por vezes, inadvertidamente subscreve a concepção de que, por exemplo, mulheres brancas, de classes médias ou elites econômicas, heterossexuais, cisgêneros, jovens ou na meia idade, magras e ocidentais "do Norte" não possuiriam, elas próprias, marcas identitárias e posicionalidades interseccionais dignas de análise e cabíveis de produzir compreensões sociais importantes acerca de processos que produzem, efetivamente, diferenças, desigualdades e, sobretudo, privilégios.

Essa ponderação, é claro, não propõe de modo algum o abandono ou a secundarização da análise interseccional das mulheres "subalternizadas", mas está sensibilizada por alguns insights propostos por Viveros Vigoya (2008, p. 19) quanto à necessidade de se "marcar a branquitude". Ou seja, de endereçar as análises interseccionais na América Latina também para grupos privilegiados em "contextos racializados". Isso auxiliaria a responder a importantes perguntas sobre os processos sociais mediante os quais mulheres e homens privilegiados são criados como agentes na reprodução do machismo e do racismo (assim como o processo de conversão do "branco" na norma e base nas quais são avaliados os demais grupos étnico-raciais). Considerando tais questões, a análise interseccional pode também obter instigantes respostas (ou talvez mesmo boas novas perguntas) se deixar de evitar a ampliação de seu escopo empírico ${ }^{30}$.

sociais (VAKALAHI \& STARKS, 2010); educação e contextos escolares (KOFOED, 2008); "subculturas de rock music" (SCHIPPERS, 2000); pesquisas de campo em contextos judiciais (COLLINS \& MOYER, 2008; BASSEL, 2010); preconceito racial e de gênero e programas de ação afirmativa (STEINBUGLER; PRESS \& DIAS, 2006); pesquisas feministas envolvendo HIV/Aids (BREDSTRÖM, 2006); experiências de lideranças de mulheres negras (JEAN-MARIE; WILLIAMS \& SHERMAN, 2009), entre inúmeras outras temáticas que se subdividem em distintas abordagens interseccionais já apontadas.

30 Além de Mara Viveros Vigoya e de autoras já citadas, há outras autoras latino-americanas ou 
Outro ponto que se torna incômodo e digno de crítica ao se ter acesso a parte do levantamento da literatura anglófona recente é, praticamente, a ausência de citações a autoras que estejam produzindo intelectualmente fora do eixo América do Norte x Europa (e a própria "Europa" acaba, na prática, limitada a alguns poucos países com produção reconhecida e de língua inglesa) ${ }^{31}$. Um exemplo desse problemático "umbiguismo anglófono" pode ser visto através de uma análise da reverberação da crítica de Chandra Talpar Mohanty (1991) em relação à visão "monolítica" das "mulheres do Terceiro Mundo" provinda de feminismos ocidentais. A referida autora, dentre os cerca de quarenta artigos sobre interseccionalidade produzidos entre o ano 2000 e o presente aos quais tive acesso, é citada por apenas oito trabalhos. Trata-se somente de um exemplo, mas citações a autoras produzindo fora dos contextos nacionais euro-norteamericanos tendem a ser flagrantemente raras em boa parte do campo recente revisado.

Quanto à possibilidade da teorização interseccional "viajar para o Sul Global", a autora Gail Lewis (2009, p. 210) se preocupa em evitar "colonizar" o pensamento de teóricas não-ocidentais, ou de países em desenvolvimento, com formas específicas de reflexão feminista. A preocupação de Lewis é, de fato, importante e prudente, no entanto, já existem pesquisas e pesquisadoras baseadas ou trabalhando em países do "Sul Global" e que tratam de tais temáticas com apuro e sofisticação superior, inclusive, a parte das publicações em língua inglesa revisadas - vide, por exemplo, o levantamento da produção interseccional latino-americana efetuado por Viveros

que pesquisaram centralmente esses contextos através de distintas análises que entrelaçavam marcadores de diferenças e desigualdades. É possível citar, por exemplo, os trabalhos de Verena Stolcke (2006), Laura Moutinho (2006), e Peter Wade (2008), Mariza Correa (1996), Angela Figueiredo (2002), entre vários outros.

31 E aqui, quando me refiro a "literatura anglófona" me remeto a autoras que publicam em língua inglesa, estejam elas produzindo ou baseadas em contextos anglófonos ou não, ou seja, adentram também, por exemplo, autoras européias de outros países que não o Reino Unido. 
Vigoya (2008). Tal produção, entretanto, parece estar sendo obliterada pela configuração contemporânea das discussões estadunidenses e européias do campo feminista interseccional.

Assim sendo, talvez o questionamento mais apropriado não seja se é efetivamente possível a teorização interseccional "viajar ao Sul Global", mas sim em atentar e considerar o que já se está sendo produzido nesses contextos - tendo em mente o fato de que o "Sul Global", em si, é uma noção generalizante, com tendências "monolíticas" e simplificadoras de universos bastante díspares e complexos, como afirma Mohanty (1991) $)^{32}$. É interessante e significativo constatar que algumas autoras, ao abordarem os fluxos teóricos globais relativos ao debate interseccional, parecem conceber como um dado a impossibilidade de teorizações relevantes sobre interseccionalidade serem desenvolvidas fora do "Centro", ou no "Sul Global". É quase como se "fazer teoria" - em particular interseccional - fosse uma prerrogativa inquestionável de teóricas feministas de países desenvolvidos, "centrais", o que parece manter tais concepções, em grande medida - mesmo quando preocupadas com a "colonização do pensamento de teóricas feministas não-ocidentais" - em um quadro epistemológico que se poderia caracterizar facilmente como eurocêntrico (e aqui, é claro, estaria inclusa a produção estadunidense).

Quiçá ignorar essa produção "descentrada" (para não dizer "periférica") - como parece estar ocorrendo em parte dos trabalhos analisados - possa ser percebida como uma postura de feminismos de países "centrais" tão ou mais problemática do que a mera preocupação com a "transmissão" de teorias do "Centro" à "Periferia" (como se as feministas "periféricas" nada mais pudessem fazer a não ser adotar passivamente as teorizações "centrais" sem resistências, diálogos ou ponderações). Assim, a impossibilidade de vias dialógicas adequadas

Mohanty (1991), aliás, mesmo que não tenda a ser lida como parte do campo feminista interseccional, acaba por oferecer uma importante contribuição ao questionar o papel da nacionalidade e das diferenças culturais na produção teórica "ocidental" feminista. 
ao debate interseccional - tendo em vista os múltiplos feminismos globais - é o que parece, à primeira vista, uma questão preocupante e que tem sido vilipendiada até o momento. Tais considerações abririam espaço, por exemplo, para novas e legítimas críticas de feministas de "países em desenvolvimento" ao que poderia ser vista como uma tendência ao apagamento de importantes reflexões e teorizações fora dos "Centros". Apagamento este que seria proveniente de uma parte desse campo de estudos interseccionais anglófonos, em particular, quando constata-se que as circulações teóricas ainda ocorrem - e são concebidas - em uma mera "via de mão única", ou seja, do "Centro" às "Periferias".

Por conseguinte, embora tais ponderações críticas, obviamente, não devam ser vistas como marcando a totalidade das autoras e dos debates apresentados, seria interessante e provocativo subvertermos a preocupação de Lewis quanto à colonização epistemológica do pensamento das feministas do "Sul Global", reformulando-a em outras bases, ou seja: na perspectiva de parte das feministas euronorteamericanas do campo interseccional seria possível que as teorizações interseccionais "descentradas" - do assim dito "Sul Global" - viagem e afetem as reflexões dos feminismos do "Norte Global"?

\section{Considerações FINAIS}

Considerando tais elementos, a intenção deste artigo primeiramentefoiadecontextualizararelevânciaeoimpactodosestudos e teorias feministas no que concerne à noção de interseccionalidade, assim como os modos como a interseccionalidade afetou e impactou tais estudos e teorias. Procurou-se frisar especialmente o modo produtivo, altamente reflexivo e complexo de distintos flancos do pensamento feminista de conceber a articulação de diferenças sociais na produção - ou na desconstrução - de desigualdades no mundo contemporâneo. 
Na sequência, pus em relevo que os debates interseccionais foram gestados sobretudo a partir das lutas e teorizações dos movimentos feministas negros e lésbicos nos Estados Unidos e Reino Unido a partir dos anos 1970, tendo algumas de suas raízes, no entanto, remontando mesmo aos movimentos abolicionistas de mulheres do século XIX. Colocar em primeiro plano esse histórico da noção de interseccionalidade como enraizado em lutas muito concretas dos movimentos feministas negros ao longo de várias ondas feministas foi um acento consciente, uma vez que, muitas vezes, tal histórico e raízes tenderam a ser apagados de modo problemático das teorizações de parte das autoras do campo interseccional.

Este trabalho procurou também condensar e sumarizar debates de modo a contribuir para que novas(os) pesquisadoras(os) possam se apropriar desse conjunto de discussões com mais facilidade e, em especial, em língua portuguesa. Afirmo isso posto que, como dito anteriormente, em meu percurso de formação na pós-graduação enfrentei dificuldades para encontrar revisões sistemáticas e extensivas sobre a interseccionalidade nos movimentos e teorizações feministas. Portanto, espero que este artigo possa auxiliar, em alguma medida, a fomentar a proliferação das reflexões do campo feminista em suas múltiplas expressões e facetas.

Dessa forma, procurei apresentar sucintamente alguns dos principais traços do percurso histórico da noção de interseccionalidade nocontextodopensamento feminista, assim comouma contextualização panorâmica das suas principais vertentes e polêmicas. Além disso, o artigo propôs, na sequência, a noção de "agência interseccional" como um elemento relevante para ser pensado e melhor desenvolvido em investigações e debates ulteriores no campo. Ademais, desenvolvi uma crítica a certos desdobramentos do debate feminista europeu e norte-americano no que diz respeito ao modo como as teorizações interseccionais poderiam (ou deveriam) "viajar ao Sul Global" sob o 
risco de um "colonialismo teórico" dos "feminismos não-ocidentais". A crítica, nesse caso, endereça-se ao modo como uma parte do campo euro-norte-americano revisado tende, em termos gerais, a ignorar, quase por completo, o que já vem sendo produzido por teóricas feministas interseccionais fora dos "países desenvolvidos" e "centrais". Nessa direção, criticou-se também a tendência de parte do campo a considerar, subrepticiamente, que teorizações interseccionais seriam uma prerrogativa de feminismos produzidos no "Centro", fechando as portas para a produção de diálogos e circulações teóricas interseccionais globais.

Espero, por fim, que esse levantamento (o qual não se propôs a ser exaustivo e certamente deixa de lado, por questões de espaço e exequibilidade, a produção de importantes autoras), assim como algumas das sugestões e críticas aqui expostas, possam ser proveitosas e contribuir às(aos) interessadas(os) na temática a se aproximarem do campo e a desenvolverem suas análises sensibilizadas pelas inúmeras vertentes, teorizações e insights que a noção de interseccionalidade pode prover.

\section{REFERÊNCIAS}

BASSEL, Leah. Intersectional politics at the boundaries of the Nation State. Ethnicities, vol 10(2), 2010, p. 155-180.

BOOGAARD, Brendy; ROGGEBAND, Conny. Paradoxes of Intersectionality: theorizing inequality in the Dutch Police Force through structure and agency. Organization, vol. 17(1), 2010, p. 53-75.

BRAH, Avtar. Travels in negotiations: difference, identity, politics. Journal of Creative Communications 2 (1\&2), 2007, p. 245-256.

BRAH, Avtar; PHOENIX, Ann. Ain't I A Woman? Revisiting intersectionality. Journal of International Women's Studies Vol 5 (3), 2004.

BRAH, Avtar. Diferença, Diversidade, Diferenciação. Cadernos Pagu, Campinas, n.26, jan./jun. 2006, p. 329-376. 
BREDSTRÖM, Anna. Intersectionality: a challenge for feminist HIV/AIDS research? European Journal of Women's Studies, vol.13(3), 2006, p. 229-243.

BREWER, Rose M. Response to Michael Buroway's Commentary 'The Critical Turn to Public Sociology'. Critical Sociology, 31, 2005, p. 353-359.

BUITELAAR, Marjo. I Am the Ultimate Challenge: accounts of intersectionality in the life-stoy of a well-known daughter of Moroccan migrant workers in the Netherlands. European Journal of Women's Studies, 13, 2006, p. 259-276.

BUTLER, Judith. Problemas de Gênero: feminismo e subversão da identidade. Rio de Janeiro, Civilização Brasileira, 2003 [1990].

BUTLER, Judith. Corpos que pesam: sobre os limites discursivos do "sexo". In: LOURO, Guacira Lopes (Org.). O corpo educado: pedagogias da sexualidade. Belo Horizonte: Autêntica, 2001.

CHRISTENSEN, Ann-Dorte. Belonging and Unbelonging from an intersectional perspective. Gender, Technology and Development, 13(1), 2009, p. 21-41.

COLLINS, Todd; MOYER, Laura. Gender, race and intersectionality on the Federal Appellate Bench. Political Research Quarterly, vol.61, n.2, 2008, p. 219-227.

COMBAHEE RIVER COLLECTIVE STATEMENT. All the Women are White, All the Blacks are Men, But Some of us are Brave. In: HULL, Gloria; BELL, Patricia Scott; SMITH, Barbara (Eds.), Nova Iorque: The Feminist Press. 1982 [1977].

CORREA, Mariza. Sobre a Invenção da Mulata. Cadernos Pagu (6-7), 1996, pp. 35-50.

CRENSHAW, Kimberlé Williams. Mapping the Margins: Intersectionality, Identity Politics, and Violence Against Women of Color. Stanford Law Review 43(6), 1991, p. 1241-99.

DAVIS, Angela. Women, Race and Class. Nova Iorque: Random House. 1981.

DAVIS, Kathy. Intersectionality as buzzword, a sociology of science perspective on what makes a feminist theory successful. Feminist Theory, vol.9(1), 2008, p. 67-85.

DENIS, Ann. Review Essay: Intersectional Analysis: A Contribution of Feminism to Sociology. International Sociology, 23, 2008, p. 677-694.

EREZ, Edna; ADELMAN, Madelaine; GREGORY, Carol. Intersections of Immigration and Domestic Violence: voices of battered immigrant women. Feminist Criminology, vol.4(1), 2009, p. 32-56.

FACCHINI, Regina. Entre Umas e Outras: mulheres (homo)sexualidades e diferenças na cidade de São Paulo. Tese de Doutorado, Ciências Sociais, Universidade Estadual de Campinas, 2008. 
FALCÓN, Sylvanna M. Black Feminist Thought. In: O'BRIEN, Jodi. (Ed.).

Encyclopedia of Gender and Society. SAGE Publications, 2009.

FIGUEIREDO, Ângela. Cabelo, cabeleira, cabeluda e descabelada: identidade, consumo e manipulação da aparência entre os negros brasileiros. Anais da $26^{\circ}$

Reunião Anual da Associação Nacional de Pós-Graduação e Pesquisa em Ciências Sociais, Caxambu, out/2002.

GILL, Rosalind. Beyond the 'Sexualization of Culture' Thesis: An Intersectional Analysis of 'Sixpacks', 'Midriffs' and 'Hot Lesbians' in Advertising. Sexualities. 12, 2009, p.137-160.

HANCOCK, A. M. When multiplication doesn't equal quick addition: Examining intersectionality as a research paradigm. Perspectives on Politics, 5, 2007, p. 63-78.

HARAWAY, Donna. Simians, cyborgs, and women. The reinvention of nature. Nova Iorque: Routledge, 1991.

HENNING, Carlos Eduardo. Paizões, Tiozões, Tias e Cacuras: envelhecimento, meia idade, velhice e homoerotismo masculino na cidade de São Paulo. Tese de Doutorado, Antropologia Social, Universidade Estadual de Campinas, 2014.

HENNING, Carlos Eduardo. As Diferenças na Diferença: hierarquia e interseções de geração, gênero, classe, raça e corporalidade em bares e boates GLS de Florianópolis, SC. Dissertação de Mestrado, Antropologia Social, UFSC, 2008a.

- Gênero, sexo e as negações do biologicismo: comentários sobre o percurso da categoria gênero. Revista Ártemis, V. 8, 2008b, p. 57-67, UFPB.

HILL COLLINS, Patricia. Black Feminist Thought: knowledge, consciousness, and the politics of empowerment. Nova Iorque: Routledge, 2000 [1990].

HILL COLLINS, Patricia. Black Sexual Politics, African Americans, Gender, and the New Racism. Routledge: New York, 2005.

hooks, bell. Ain't I a Woman? Black women and feminism. Cambridge, MA: South End, 1981.

hooks, bell. Intelectuais Negras. Revista Estudos Feministas, n.2, 1995, p. 464-478.

HULKO, Wendy. The time - and context - contingent nature of intersectionality and interlocking oppressions. Affilia: Journal of Women and Social Work. Vol. 24, 2009, p. 44-55.

JEAN-MARIE, Gaetane; WILLIAMS, Vicki A.; SHERMAN, Sheila. Black Women's Leadership Experiences: examining the intersectionality of race and gender. Advances in Developing Human Resources, 11(5), 2009, p. 562-581. 
KNAPP, Gudrun-Axeli. Race, Class, Gender: Reclaiming Baggage in Fast Travelling Theories. European Journal of Women's Studies Vol. 12(3), 2005, p. 249-265.

KOFOED, Jette. Appropriate Pupilness: social categories intersecting in school. Childhood, 15, 2008, p. 415-430.

LÉPINARD, Eléonore. 2010. In the Name of Equality? The missing intersection in Canadian feminists' legal mobilization against multiculturalism. American Behavioral Scientist, 53(12), p.1763-1787.

LEWIS, Gail. Editorial. Celebrating Intersectionality? Debates on a multi-faceted concept in gender studies: themes from a conference. European Journal of Women's Studies. 16, 2009, p. 203-210.

LORDE, Audrey. Sister Outsider. Trumansberg: The Crossing Press, 1984.

MAZZEI, Julie; O'BRIEN, Erin. You Got It, So When Do You Flaunt It? Building rapport, intersectionality, and the strategic deployment of gender in the field. Journal of Contemporary Ethnography, Vol 28, n. 3, 2009, p. 358-383.

McCALL, Leslie. The complexity of intersectionality. Signs: Journal of Women in Culture and Society. Vol. 30, n.3, 2005, p. 1771-1800.

McKLINCTOCK, Anne. Imperial leather, Race, gender and sexuality in the colonial contest. Nova Iorque: Routledge, 1995.

MIESCHER, Stephan. Editorial. Masculinities, intersectionality, and collaborative approaches. Men and Masculinities, vol.11 n.2, 2008, p. 227-233.

MOHANTY, Chandra Talpar. Under Western Eyes: Feminist Scholarship and Colonial Discourses. In: MOHANTY, C. T.; RUSSO, A; TORRES,L. (Ed). Third World Women and the politics of feminism. Bloomington: Indiana University Press, 1991.

MOUTINHO, Laura. Negociando com a adversidade: reflexões sobre 'raça', (homos) sexualidade e desigualdade social no Rio de Janeiro. Revista Estudos Feministas. Vol.14, n.1, 2006, p. 103-116.

PHOENIX, Ann; PATTYNAMA, Pamela. Editorial: Intersectionality. European Journal of Women's Studies, 13, 2006, p.187-192.

PISCITELLI, Adriana. Interseccionalidade, categorias de articulação e experiências de migrantes brasileiras. Sociedade e Cultura, v.11, n.2, jul/dez, 2008, p. 263-274.

PRINS, Baukje. Narrative accounts of origins: a Blind Spot in the Intersectional Approach? European Journal of Women's Studies, v. 13, n. 3, 2006, p. 277-290.

ROSALDO, Michelle. O uso e o abuso da antropologia: reflexões sobre o feminismo e o entendimento intercultural. Horizontes Antropológicos, ano 1, n.1, 1995, p.11-36. 
SCHIPPERS, Mimi. The social organization of sexuality and gender in alternative hard rock: an analysis of intersectionality. Gender \& Society, 14, 2000, p. 747-764.

SCOTT, Joan. Gênero: uma categoria útil de análise histórica. Educação e Realidade, vol.16, n.2, 1990 [1988], p. 5-22.

STEINBUGLER, Amy; PRESS, Julie; DIAS, Janice Johnson. Gender, race and affirmative action: operationalizing intersectionality in survey research. Gender $\mathcal{E}$ Society, 20, 2006, p. 805-825.

STOLCKE, Verena. O enigma das interseções: classe, "raça", sexo, sexualidade. A formação dos impérios transatlânticos do século XVI ao XIX. Revista Estudos Feministas, Florianópolis, 14(1), 2006, p. 15-42.

STRATHERN, Marilyn. O gênero da dádiva: problemas com as mulheres e problemas com a sociedade na Melanésia. Campinas, Editora da Unicamp, 2006 [1988].

TWINE, Richard. Intersectional disgust? Animals and (eco)feminism. Feminism \& Psychology, 20(3), 2010, p. 397-406.

VAKALAHI, Halaevalu; STARKS, Saundra. The Complexities of Becoming Visible: reflecting on the stories of women of color as social work educators. Affilia: Journal of Women and Social Work, 25(2), 2010, p. 110-122.

VERLOO, Mieke. Multiple inequalities, intersectionality and the European Union. European Journal of Women's Studies, 13, 2006, p. 211-228.

VIVEROS VIGOYA, Mara. La sexualización de la raza y la racialización de la sexualidad en América Latina. Seminario Internacional La sexualidad frente a la sociedad, Cidade do México, 28-31 de julio de 2008.

WADE, Peter. Debates contemporáneos sobre raza, etnicidad, género y sexualidad en las ciencias sociales. In.: WADE, P; VIVEROS VIGOYA, M; GIRALDO, F. (Coord.) Raza, etnicidade y sexualidades: ciudadanía y multiculturalismo en América Latina. Bogotá: Universidad Nacional de Colombia/Facultad de Ciencias Humanas/Centro de Estudios Sociales/Escuela de Estudios de Género, 2008.

WALBY, Sylvia. Complexity theory, systems theory and multiple intersecting social inequalities. Philosophy of the Social Sciences, 37, 2007, p. 449-470.

YUVAL-DAVIS, Nira. Intersectionality and feminist politics. European Journal of Women's Studies, 13, 2006, p. 193-209.

ZERAI, Assata. Agents of Knowledge and Action: selected Africana Scholars and their contributions to the understanding of race, class and gender intersectionality. Cultural Dynamics, 12, 2000, p.182-222. 